\title{
Covariation between eumelanic pigmentation and body mass only under specific conditions
}

\begin{abstract}
Alexandre Roulin
Received: 3 August 2008 /Revised: 17 November 2008/Accepted: 24 November 2008/Published online: 3 January 2009

(C) Springer-Verlag 2008
\end{abstract}

\begin{abstract}
Identifying the factors that mediate covariation between an ornament and other phenotypic attributes is important to determine the signaling function of ornaments. Sign and magnitude of a covariation may vary across environments if the expression of the ornament or of its linked genes regulating correlated phenotypes is conditiondependent. I investigated in the barn owl Tyto alba whether sign and magnitude of covariation between body mass and two heritable melanin-based plumage ornaments change with food supply, along the reproductive cycle and from the morning to the evening. Using a dataset of 1,848 measurements of body mass in 336 breeding females, I found that females displaying large black spots were heavier than conspecifics with smaller spots in the afternoon (i.e., a long time after the last feeding) but not in the morning (i.e., a short time after the last feeding). This is consistent with the recently proposed hypothesis that eumelanin-based ornaments are associated with the ability to maintain energy balance between food intake and energy expenditure. Thus, covariation between melanin-based coloration and body mass can be detected only under specific conditions potentially explaining why it has been reported in only ten out of 28 vertebrate species. The proposition that ornamented individuals achieve a higher fitness than drab conspecifics only in specific environments should be tested for other ornaments.
\end{abstract}

Keywords Body mass - Melanin-based coloration . Polymorphism $\cdot$ Sexual selection $\cdot$ Female ornament

\footnotetext{
A. Roulin $(\square)$

Department of Ecology and Evolution, Biophore,

University of Lausanne,

1024 Lausanne, Switzerland

e-mail: Alexandre.Roulin@unil.ch
}

\section{Introduction}

Conspicuous ornaments can signal aspects of individual quality. Following signaling theory ornaments can advertise quality if there is a trade-off between the allocation of resources to produce an ornament and to other activities associated with body maintenance (e.g., Gustafsson et al. 1995). In that case, only individuals in prime condition can afford to produce and wear a conspicuous trait (Andersson 1994; Johnstone 1995), and thus, ornamented individuals should achieve a higher fitness than drab conspecifics. Individuals displaying different values of an ornament may also be adapted to different environments and thus represent equally fit alternative strategies (Gross 1996; Galeotti et al. 2003). From a proximate point of view, alternative strategies may be advertised with elaborate traits such as coloration if there is a linkage disequilibrium between genes coding for coloration and those coding for other physiological processes. Each allele would code for a specific color and physiological properties that allow each color morph to exploit a specific environment (Ducrest et al. 2008; Gratten et al. 2008). Finally, ornamented individuals may achieve a higher fitness but only under specific conditions, and thus, a covariation between an ornament and other phenotypes may be detected only under these specific conditions (Järvi et al. 1987; Gonzales et al. 1999). This situation may occur if the expression of genes coding for the associated phenotypes is sensitive to environmental factors. As a consequence, the intensity of sexual selection may vary over time and space (e.g., Chaine and Lyon 2008).

A few studies have investigated whether environmental factors mediate sign and magnitude of a covariation between an ornament and other phenotypic attributes. In the house sparrow (Passer domesticus), response to an immune challenge was stronger in blacker individuals in 
November but weaker in April (Gonzales et al. 1999) suggesting that some environmental factors mediate sign and magnitude of the covariation between eumelanin-based coloration and immunity. In nestling European kestrels (Falco tinnunculus), eumelanin-based coloration was positively correlated with body mass in individuals treated with testosterone but not in control individuals. As injection of testosterone impaired offspring body mass and response to an immune challenge (Fargallo et al. 2007a), eumelanic individuals were therefore better able to regulate body mass when testosterone was experimentally increased than lightly eumelanic conspecifics. Finally, in the Alpine swift (Apus melba), offspring of darker eumelanic fathers grew more rapidly when raised in foster broods for which the number of nestlings was experimentally enlarged but not when reduced (Roulin et al. 2008a).

To examine the hypothesis that covariation between melanin-based traits and aspects of phenotypic quality varies across environments, I performed a correlative study in the barn owl. Such a study is important because it has the potential to reveal that different values of an ornament are associated with adaptations to specific conditions. For instance, to be darkly colored might be advantageous in some circumstances but not in others. This is a key aspect when considering the role of environmental heterogeneity in the maintenance of polymorphism (Kassen 2002; Kawecki and Ebert 2004). In this context, barn owls are particularly interesting because the body underside varies continuously from immaculate to heavily marked with black spots (a eumelanin-based trait) and from reddishbrown to white (a phaeomelanin-based trait, Roulin et al. 2008b), two heritable traits for which the expression is not sensitive to the environment, at least not to a detectable degree in nestlings (Roulin and Dijkstra 2003, Roulin 2004a but see Roulin et al. 2008b). Number and size of black spots are positively correlated, while phaeomelaninbased coloration is correlated with number of spots and to a low extent to spot size in males but not in females (darker reddish-brown birds are more heavily spotted; Roulin 2004a). Although individuals of each sex can show any phenotype, females display on average more and larger black spots and they are darker reddish-brown than males. Experiments suggest that males assess the size of female black spots to choose a mate (Roulin and Altwegg 2007) and to adjust feeding effort (Roulin 1999).

In the present study, I considered the covariation between body mass and melanin-based coloration because we recently proposed that genes coding melanogenesis also regulate food intake and energy expenditure (Ducrest et al. 2008). A thorough review of genetic and pharmacological studies indeed showed that binding of melanocortin hormones to melanocortin 1-receptors (MC1R) triggers the production of black eumelanins, while binding of melanocortins to MC3R and MC4R regulate the central and peripheral control of energy homeostasis. I thus investigated whether melanin-based pigmentation covaries with body mass and whether this covariation is detected only under specific conditions. Between 1991 and 2007, I weighed breeding female barn owls to assess the role of variation in access to food stores (i.e., prey remains lying in nests during daylight hours), reproductive cycle (i.e., from incubation to offspring rearing), and hour of the day on the sign and magnitude of covariation between body mass and melanin-based coloration. The hypothesis that eumelaninbased coloration is associated with the balance between energy intake and expenditure (Ducrest et al. 2008; Roulin et al. 2008a) predicts that females displaying large black spots may be heavier than individuals displaying smaller spots when they do not have access to prey remains, when rearing offspring rather than during incubation, and in the afternoon rather than in the morning. In the following, I explain the rationale of these three predictions.

1. Because during daylight hours breeding barn owls frequently eat prey remains stored the previous night in their nest (Roulin 2004b), I could test whether sign and magnitude of a covariation between body mass and melanin-based coloration depends on whether females had still access to prey remains. As the quantity of prey remains varies from day to day, this test may indicate whether pigmented or less pigmented females perform better in days when food is available in large or low quantity.

2. Female barn owls lose one-quarter of body mass from the beginning to the end of the reproductive season, and thus, covariation may vary along the reproductive cycle if it is sensitive to the accumulation of fatigue due to investment in reproduction. Thus, if the covariation between body mass and eumelanin-based coloration changes along the reproductive cycle, this may indicate that differently colored individuals invest differentially in reproduction.

3. Finally, because barn owls eat primarily at night, they naturally lose body mass from the early morning to the end of the afternoon. Hence, covariation may change in magnitude with hour of the day if differently plumaged birds differ in digestive efficiency.

\section{Materials and methods}

\section{Study organism}

The barn owl is monogamous, medium-sized, nocturnal, and feeds primarily upon small mammals. As in other raptors and owls, females are on average heavier than 
males. In Switzerland, barn owls produce one or two clutches per year from 24th of February to the 4th of August. Clutch size ranges from 2 to 11 with each egg being laid every 2.5 days; only the female parent incubates each egg during ca 32 days starting as soon as the first egg has been laid. Mothers brood their hatchlings and distribute among them food collected by the father. Once the offspring are thermo-independent at 2 to 3 weeks of age, the mother begins to help her partner deliver prey items to the progeny (Roulin 2002). At 3 to 4 weeks of age, the mother is usually no more in her nest during daylight hours. At night, parents often store food in their nest to be consumed by offspring and mother (if present in their nest) during daylight hours; the father is rarely with her partner at that time. The proportion of nests with at least one prey item found uneaten in nestboxes decreases from ca $80 \%$ at hatching to $15 \%$ at fledging which takes place when nestlings are ca 2-month-old. The mean number of prey remains per nestling per nest varies from three to four at hatching to less than one item around fledging time (Roulin 2004b). Therefore, the quantity of prey remains available to females decline along the course of the reproductive cycle because females are in their nest during daylight hours in the first half of the reproductive cycle when prey remains are more abundant. Barn owls are not known to store food outside their nest.

\section{Measurement of female body mass and plumage traits}

The study was performed in western Switzerland in an area covering $30 \times 7 \mathrm{~km}$ where 110 nest-boxes were put up in barns. I measured wing length of the first-hatched nestling to estimate hatching date (see Roulin 2004b). During the first 78 days after the start of egg laying (mean $\pm \mathrm{SE}$ : 38.1 days \pm 0.4 ), each of 336 females was weighed on average $5.50 \pm 0.28$ times (range $=1-44$; median $=4$ ) totaling 1,848 measurements. Captures took place between 7:00 A.M. and 1:30 A.M. (median is 3:15 P.M.). I found at least one prey remain at 972 of the 1,848 nest visits $(52.6 \%)$, and I weighed all prey remains to the nearest gram. I did not consider males because most individuals were captured only once per year, at night and while feeding the offspring.

From 1996 to 2007 I reliably assessed phaeomelaninbased coloration on the breast by comparison with eight color chips with one for dark reddish-brown to eight for white (Roulin 1999). Coloration is homogenous with all feathers being similarly colored. For 332 of the 336 individuals, I collected a feather on the breast, and in 2007, I measured reflectance in the range 400-700 nm (visible spectrum) using an Ocean Optics S2000 spectrometer and a PX-2 xenon lamp (Ocean Optics, Duiven, the Netherlands). Coloration scored in the field, and reflectance was correlated (Pearson correlations, $r=-0.73, n=332, P<$
0.0001). Analyses performed using reflectance data or coloration scored in the field gave qualitatively similar results, and for this reason, I present only results using coloration scored in the field as in previous papers.

On the same body part measuring approximately $70 \times$ $50 \mathrm{~mm}$, I counted and measured black spots with a caliper to the nearest $0.1 \mathrm{~mm}$ within a $60 \times 40 \mathrm{~mm}$ frame; a mean spot diameter value was calculated and used in the statistical analyses (Roulin 2004a). Because a previous study showed that spot diameter rather than number of spots is associated with other phenotypic attributes (Roulin 2004a), I considered only spot diameter to simplify the statistical analyses. This method is justified because number of spots was not associated with female body mass alone or in interaction with other variables (results not shown). I did not consider the intensity of spot darkness because spots are lighter colored when feathers are older implying that this variable depends on the degree of abrasion. Individuals that are redder and more spotted than another one in 1 year are still redder and more spotted in other years (Roulin and Dijkstra 2003), and thus, I considered mean trait values for individuals captured on several occasions. I assigned these mean values to 39 individuals for which body mass was measured on 118 occasions before 1996. If I exclude the data taken before 1996, I obtain qualitatively similar results (not shown). Age in years was known with accuracy when birds had been ringed as nestlings. Otherwise, the birds were classified as "yearling" if their primary and secondary wing feathers belonged to the same new generation, and 2year-old otherwise (Taylor 1993). The oldest individual recorded in the study area was 16 years old. Spot diameter was associated neither with hour of the day when females were weighed nor with reproductive cycle (i.e., number of days between the dates when females were weighed and their first egg had been laid; mixed model analysis of covariance (ANCOVA) with year and female identity as two random factors, $P$ values $>0.26$ ).

Potential fitness consequences of body mass regulation

To assess the potential fitness consequences of body mass regulation, between 1994 and 2007, I weighed 212 females during incubation, i.e., between 21 and 32 days after the start of egg laying. Each individual was weighed once per year with an average of $1.36 \pm 0.05$ measurement per female (range 1-6). This was useful to examine whether females incubating larger clutches are heavier.

\section{Statistical analysis}

Using the JMP statistical package version 7, I performed a two-tailed mixed-model ANCOVA with body mass as the dependent variable, and as two random variables female 
identity and year. Independent fixed variables were phaeomelanin-based coloration and mean spot diameter, presence/absence of prey remains in nest-boxes (hereafter "prey remain"), hour of the day ("hour") and number of days between the dates when females were weighed and their first egg had been laid ("reproductive cycle"). I also entered female age as a fixed independent variable because females become whiter and display larger black spots between the first- and second-year of age (Roulin and Altwegg 2007) and because female body mass may change with age. As I am interested in testing whether phaeomelanic coloration and spot size covary with body mass only in specific conditions, I entered all interactions between prey remain, hour, reproductive cycle and the two plumage traits. I ran a full model and nonsignificant terms $(P>0.05)$, starting with nonsignificant interactions were backward dropped from the model. The final model reported in Table 1 contained only significant effects, and main effects involved in significant interactions. Body mass values and residuals extracted from the statistical models were normally distributed, and residuals were not correlated with predicted body mass values. Means are quoted $\pm \mathrm{SE}$

\section{Results}

Female body mass varied between 264 and $515 \mathrm{~g}$ with a mean value of $367 \pm 0.8 \mathrm{~g}$. As owls consume food during daylight hours (Roulin 2004b), females were significantly heavier when I found at least one prey remain in their nest compared to a situation without prey remain $(374.0 \pm 1.4 \mathrm{~g}$ vs. $360.7 \pm 1.5 \mathrm{~g}$; term "prey remains" in Table 1). Females lost $97.3 \pm 2.1 \mathrm{~g}$ from the start of egg laying to when their offspring were 46 days of age (significant term "reproductive cycle" in Table 1), they lost 12.8 $\pm 2.3 \mathrm{~g}$ from 7:00 A.M. to 1:30 A.M. (significant term "hour" in Table 1), and per year of age females gained $2.2 \pm 0.4 \mathrm{~g}$ (significant term "age" in Table 1).

As predicted by the hypothesis that eumelanin-based coloration is associated with the ability to regulate the balance between energy intake and expenditure, females displaying large black spots were significantly heavier than females with smaller spots particularly in the afternoon (interaction hour $\times$ spot diameter in Table 1; Fig. 1). Phaeomelanin-based coloration was associated with body mass in interaction with hour of the day $(P=0.06)$; this relationship was however not significant $(P=0.19)$ if I removed spot diameter from the model, while the effect of spot diameter on body mass remained significant $(P=$ 0.0028 ) after having removed phaeomelanin-based coloration from the model. In a mixed model ANOVA including spot diameter and hour as the only two independent variables, the interaction was still significant $\left(F_{1,1765}=\right.$ 12.91, $P=0.0003$ ) showing that this relationship proved significant without entering the variables "reproductive cycle" and "prey remains" in the same model. In Table 1, interaction between "hour" and "prey remains" was significant because the decline in body mass from the morning to the evening was more pronounced in absence than presence of prey remains. Interaction between "hour" and "reproductive cycle" was significant because the decline in body mass from the morning to the evening increased from egg laying to offspring rearing.

The significant interaction between spot diameter and hour of the day on female body mass could be due to differential access to food resources if heavily spotted females are located in nests with more prey remains than lightly spotted individuals. To test for this possibility, I performed a logistic regression analysis with presence (1) and absence ( 0 ) of prey remains during daylight hours as the dependent variable, female identity, and year as two random factors, and hour, reproductive cycle and spot

Table 1 Mixed model ANCOVAs with female body mass as dependent variable

\begin{tabular}{lrccc}
\hline Source & \multicolumn{1}{c}{ F } & $d f$ & $P$ & Estimate \pm SE \\
\hline Prey remains & 212.14 & 1,1640 & $<0.0001$ & $-7.18 \pm 0.49$ \\
Reproductive cycle & 2104.58 & 1,1613 & $<0.0001$ & $-1.25 \pm 0.03$ \\
Hour & 32.17 & 1,1614 & $<0.0001$ & $-0.69 \pm 0.12$ \\
Spot diameter & 6.11 & $1,339.3$ & 0.014 & $0.78 \pm 0.31$ \\
Phaeomelanin-based coloration & 3.17 & $1,349.6$ & $<0.0001$ & $1.66 \pm 0.93$ \\
Age & 31.61 & $1,688.1$ & $<0.0001$ & $-0.61 \pm 0.39$ \\
Hour x prey remains & 27.97 & 1,1634 & 0.0054 & $-0.02 \pm 0.0007$ \\
Hour $\times$ reproductive cycle & 7.77 & 1,1627 & 0.06 & $0.17 \pm 0.09$ \\
Hour $\times$ pheomelanin-based coloration & 3.47 & 1,1664 & 0.0004 & $0.11 \pm 0.03$ \\
Hour $\times$ spot diameter & 12.68 & 1,1635 &
\end{tabular}

Presence of prey remains (yes/no) is a fixed factor, and reproductive cycle (i.e., number of days between the dates when the first egg had been laid and females weighed), hour of the day, spot diameter, phaeomelanin-based coloration, and female age are five covariates. Female identity and year are included as two random factors. $F$-values, degrees of freedom, $P$ values are reported for the fixed effects. Estimates $( \pm \mathrm{SE})$ are the coefficients of the linear model found by least squares. This is the final model after stepwise elimination of nonsignificant interactions 


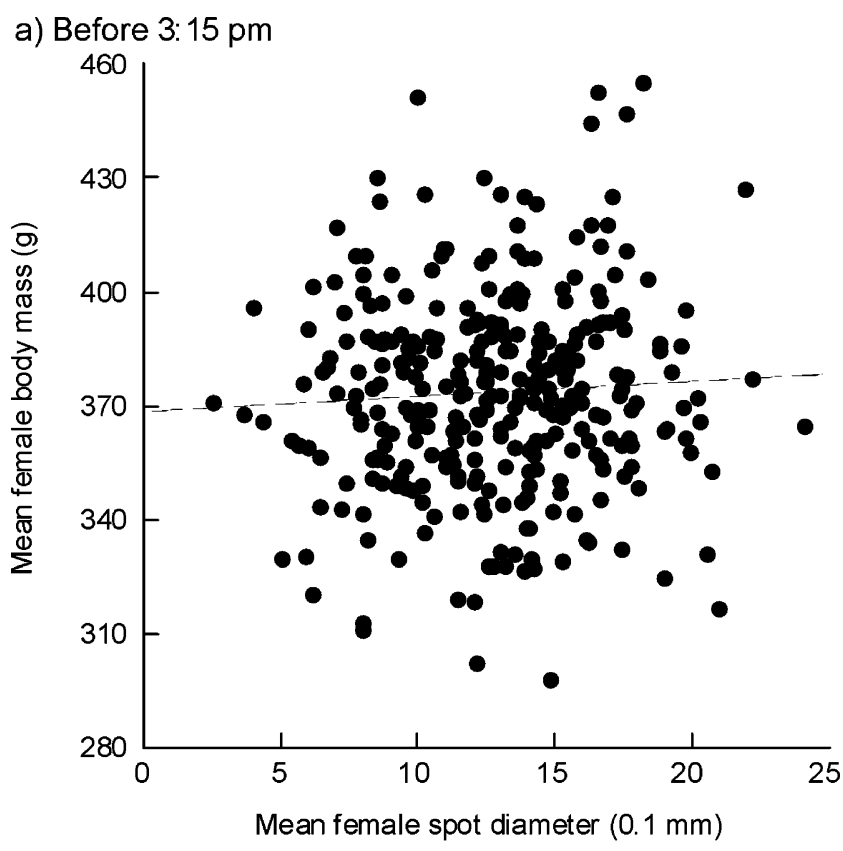

b) After 3:15 pm

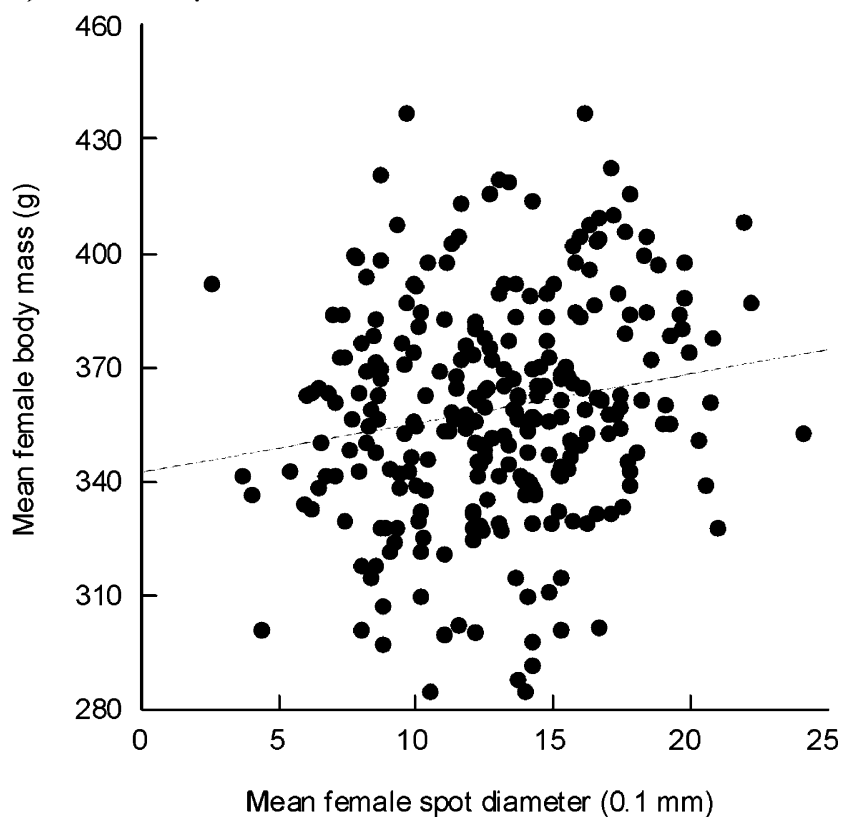

Fig. 1 Relationship between mean female body mass and mean female spot diameter $\mathbf{a}$ before and $\mathbf{b}$ after 3:15 P.M. (median hour of the day when females were weighed). I calculated mean values for individuals captured more than once and thus each female appears only once per figure. Female body mass was associated with spot diameter in the afternoon (Pearson correlation on mean values calculated for each female: $r=0.17, n=271$ different females, $P=$ 0.0046; Fig. 1b) but not in the morning (similar analysis: $r=0.06, n=$ 308 different females, $P=0.32$; Fig. 1a). Regression line is drawn for illustrative purposes

diameter as three independent variables plus all interactions. Spot diameter was neither significant alone nor in interaction $(P$ values $>0.47)$. After having excluded measurements when no prey remain was found, the total amount of prey remains found in nests (expressed in grams) was associated neither with spot diameter alone nor in interaction (mixed model ANOVA with year and female identity as random factors, and as independent variables, hour, reproductive cycle and spot diameter, plus all possible interactions; $P$ values $>0.24$ ). Thus, access to prey remains during daylight hours was not associated with female spot diameter.

Female body mass measured during incubation was positively associated with clutch size suggesting that a better regulation of body mass is beneficial (mixed model ANOVA with year and female identity as two random variables, clutch size as dependent variable, female body mass as first independent variable: $F_{1,267.5}=P<0.0001$, Fig. 2; laying date as second independent variable: $F_{1,271.5}=P<0.0001$ ).

\section{Discussion}

Previous studies have hypothesized that eumelanin-based coloration signals adaptation to stressful environments (Ducrest et al. 2008). This hypothesis is based on the findings that in large broods, nestling Alpine swifts grow more rapidly when their biological father is darker eumelanic (Roulin et al. 2008a), and an experimental increase in blood circulating corticosterone affects feeding rate to a lower extent in dark than lightly eumelanic male barn owls (Almasi et al. 2008). In the present paper, I

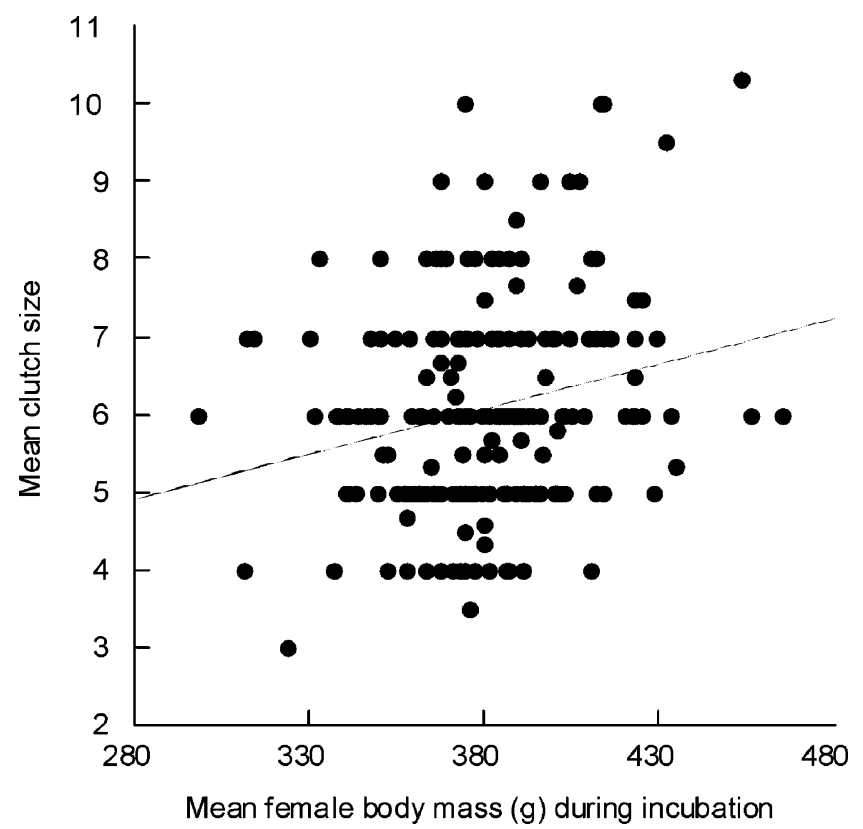

Fig. 2 Relationship between mean clutch size and mean female body mass (g) measured during incubation. For each individual captured in more than 1 year, a mean value was calculated, and thus, each female appears only once in this figure. Pearson correlation. $r=0.22, n=212$, $P<0.0001)$. Regression line is drawn for illustrative purposes 
Table 2 Review of studies that investigated the relationship between the degree of eumelanin-based coloration and body mass within populations of vertebrates

\begin{tabular}{|c|c|c|c|}
\hline Sign of covariation & Species & Order & Reference \\
\hline+ & Eurasian dotterel (Charadrius morinellus) & Bird & Owens et al. 1994 \\
\hline+ & House sparrow (Passer domesticus) & Bird & Nakagawa et al. 2007 \\
\hline+ & Kentucky warbler (Oporornis formosus) & Bird & Parker et al. 2003 \\
\hline+ & Red-legged partridge (Alectoris rufa) & Bird & Bortolotti et al. 2006 \\
\hline+ & Soay sheep (Ovis aries) & Mammal & Clutton-Brock et al. 1997 \\
\hline+ & Adder (Vipera berus) & Reptile & Andren and Nilson 1981, Monney et al. 1996 \\
\hline- & Spadefoot toad (Scaphiopus couchii) & Amphibian & Vasquez and Pfennig 2007 \\
\hline- & Least auklet (Aethia pusilla) & Bird & Jones 1990 \\
\hline- & Asp viper (Vipera aspis) & Reptile & Monney et al. 1996 \\
\hline 0 & Alpine swift (Apus melba) & Bird & Roulin et al. 2008a \\
\hline 0 & American goldfinch (Carduelis tristis) & Bird & Rosen and Tarvin 2006 \\
\hline 0 & Arctic skua (Stercorarius parasiticus) & Bird & Phillips and Furness 1998 \\
\hline 0 & Bananaquit (Coereba flaveola) & Bird & Wunderle 1981 \\
\hline 0 & Barn owl (Tyto alba) & Bird & Roulin 2006 \\
\hline 0 & Common yellowthroat (Geothlypis frichas) & Bird & Tarof et al. 2005; Thusius et al. 2001 \\
\hline 0 & European kestrel (Falco tinnunculus) & Bird & Fargallo et al. 2007b, Wiehn and Korpimäki 1997 \\
\hline 0 & Feral pigeon (Columbia livia) & Bird & Murton et al. 1973 \\
\hline 0 & Great tit (Parus major) & Bird & Järvi and Bakken 1984 \\
\hline 0 & Lesser grey shrike (Lanius minor) & Bird & Kristin et al. 2007 \\
\hline 0 & Lesser kestrel (Falco naumanni) & Bird & Tella et al. 1997 \\
\hline 0 & Northern cardinal (Cardinalis cardinalis) & Bird & Jawor et al. 2004 \\
\hline 0 & Pied flycatcher (Ficedula hypoleuca) & Bird & Potti and Montalvo 1991, Slagsvold and Lifjeld 1988 \\
\hline 0 & Red-billed queleas (Quelea quelea) & Bird & Dale 2000 \\
\hline 0 & Siskin (Carduelis spinus) & Bird & Senar et al. 2000 \\
\hline 0 & Snow goose (Chen caerulescens caerulescens) & Bird & Cooke et al. 1995 \\
\hline 0 & Green swordtail (Xiphophorus helleri) & Fish & Meyer et al. 2006 \\
\hline 0 & Guppy (Poecilia reticulata) & Fish & Hughes et al. 2005 \\
\hline
\end{tabular}

The signs "+" and "-" indicate whether researchers found a significant positive (i.e., dark individuals were heavier than lighter-colored conspecifics) or negative covariation (i.e., darker individuals were less heavy), while " 0 " indicates cases where eumelanin-based coloration was not significantly associated with body mass

investigated three predictions of the hypothesis that eumelanin-based pigmentation is associated with the ability to regulate energy balance and hence body mass. The strength of the covariation between body mass and eumelanin-based coloration was sensitive to hour of the day (i.e., variable "hour" in Table 1) but neither to the reproductive cycle nor to the presence of prey remains in the nest. The absence of effect of the variable "reproductive cycle" on the covariation between body mass and spot size indicates that change in body mass from the incubation stage to the period when females hunt for the offspring is not associated with eumelanin-based coloration. This suggests that females displaying small and large spots invest similarly in reproduction, a proposition that should be tested experimentally for instance by manipulating brood size. As access to prey remains was not associated with spot diameter, the absence of effect of the variable "prey remains" suggests that differently spotted females do not differ in the capacity to cope with short-term variation in food supply. Females are indeed heavier in days when prey remains are available in their nest compared to a situation without prey remains ( 374.0 vs. $360.7 \mathrm{~g}$ ), but the difference in body mass between heavily and lightly spotted females did not differ between these two situations.

As owls eat mainly at night, the finding that the covariation between body mass and spot diameter was stronger in the evening than in the morning could be explained by differential water loss, defecation, or digestive rate during daylight hours by heavily and lightly spotted individuals. From a genetic point of view, results of the present study are consistent with a novel hypothesis proposing that the degree of eumelanin-based coloration is associated with the ability to regulate the balance between energy intake and expenditure (Ducrest et al. 2008). It will be interesting to test whether eumelanic females were heavier than lightly spotted females in the evening because of higher melanocortin levels. To test the hypothesis that covariation between eumelanin-based coloration and body mass is stronger when birds are fasting, an experimental approach should be adopted with a group of individuals being offered food in the morning while another group of individuals is being kept without food. With this design, we 
could examine whether the relationship between spot size and body mass in the evening is stronger when individuals are food-deprived compared to offered food ad libitum. To get further insight into the physiological mechanisms underlying this covariation, the rate of fat deposition should also be assessed, for instance by measuring triglyceride level, since melanocortins regulate fat deposition (Nogueiras et al. 2007).

Assuming that the degree of eumelanin-based coloration is associated with the ability to regulate energy homeostasis not only in the barn owl but also in other vertebrates, why did this color trait not covary with body mass in $64 \%$ of studied vertebrate species (Table 2)? Two explanations can be put forward. First, interindividual variation in the degree of eumelanin-based coloration may not always be due to variation in melanocortin levels but to downstream effectors of melanogenesis such as mutations at $M C 1 R$ as shown in 13 out of $23(57 \%)$ vertebrate species (Ducrest et al. 2008). The exact proportion of animals for which interindividual variation in melanin-based coloration is due to mutations at $M C 1 R$ is probably much less than $57 \%$ as researchers have sequenced this gene mainly in species in which there is a clear color polymorphism and, thus, in species in which variation in coloration is probably due to a gene having major phenotypic effects such as $M C 1 R$. In other words, the choice of species for which $M C 1 R$ was sequenced (and published) is not random. Second, covariation between eumelanin-based coloration and body mass may be condition-dependent if differential melanocortin production by darkly and lightly colored individuals is exacerbated under specific environmental or social conditions. In line with this proposition, the level of circulating melanocortins is higher in laboratory rats fed ad libitum compared to food-deprived mice (Caminos et al. 2008). A similar physiological mechanism may explain why heavily spotted females were heavier in the evening, a couple of hours after the last meal.

Assessing the mechanism that underlies the covariation between eumelanin-based coloration and body mass is a key to understand both the adaptive function of melaninbased ornaments but also why such ornaments are a criterion in mate choice decisions (e.g., Burley 1977, Houtman and Falls 1994; Fox et al. 2002; Dunn et al. 2008). Knowledge of this mechanism will allow researchers to predict under which environmental or social situations darker eumelanic individuals have an advantage over lightly eumelanic conspecifics and thus under which conditions eumelanic individuals should be preferred as mates. Assuming that eumelanin-based coloration is indeed associated with aspects of individual quality in some specific environments, darker individuals may be preferred as mates over lightly colored conspecifics more strongly in those environments (Jennions and Petrie 1997). The framework used in the presented study for melanin-based ornaments should be extended to other ornaments. This might shed light on the conditions under which individuals derive the largest fitness benefits of being ornamented.

Acknowledgements The Swiss National Science Foundation financed this project (grant PP00A-102913). I am grateful to Bettina Almasi, Anne-Lyse Ducrest, the late Martin Epars, and Henri Etter for their help during the fieldwork.

\section{References}

Almasi B, Roulin A, Jenni-Eiermann S, Jenni L (2008) Parental investment and its sensitivity to corticosterone is linked to melanin-based coloration in barn owls. Horm Behav 54:217-223

Andersson M (1994) Sexual selection. Princeton University Press, Princeton

Andren C, Nilson G (1981) Reproductive success and risk of predation in normal and melanistic color morphs of the adder, Vipera berus. Biol J Linn Soc Lond 15:235-246

Bortolotti GR, Blas J, Negro JJ, Tella JL (2006) A complex plumage pattern as an honest social signal. Anim Behav 72:423-430

Burley N (1977) Parental investment, mate choice, and mate quality. Proc Natl Acad Sci USA 74:3476-3479

Caminos JE, Bravo SB, Gonzales CR, Garces MF, Cepeda LA, Gonzalez AC, Cordido F, Lopez M, Dieguez C (2008) Food intake regulating-neuropeptides are expressed and regulated through pregnancy and following food restriction in rat placenta. Reprod Biol Endocrinol 6:14

Chaine AS, Lyon BE (2008) Adaptive plasticity in female mate choice dampens sexual selection on male ornaments in the lark bunting. Science 319:459-462

Clutton-Brock TH, Wilson K, Stevenson IR (1997) Density-dependent selection on horn phenotype in Soay sheep. Phil Trans R Soc Lond B352:839-850

Cooke F, Rockwell RF, Lank DB (1995) The snow geese of la Pérouse Bay. Natural selection in the wild. Oxford University Press, Oxford

Dale J (2000) Ornamental plumage does not signal male quality in red-billed queleas. Proc R Soc Lond B267:2143-2149

Ducrest A-L, Keller L, Roulin A (2008) The melanocortin system, coloration and behavioural syndromes. Trends Ecol Evol 23:502-510.

Dunn PO, Whittingham LA, Freeman-Gallant CR, DeCoste J (2008) Geographic variation in the function of ornaments in the common yellowthroat Geothlypis trichas. J Avian Biol 39:66-72

Fargallo JA, Martínez-Padilla J, Toledano-Díaz A, Santiago-Moreno J, Dávila JA (2007a) Sex and testosterone effects on growth, immunity and melanin coloration of nestling Eurasian kestrels. J Anim Ecol 76:201-209

Fargallo JA, Laaksonen T, Korpimaki E, Wakamatsu K (2007b) A melanin-based trait reflects environmental growth conditions of nestling male Eurasian kestrels. Evol Ecol 21:157-171

Fox S, Brooks R, Lewis MJ, Johnson CN (2002) Polymorphism, mate choice and sexual selection in the Gouldian finch (Erythrura gouldiae). Austr J Zool 50:125-134

Galeotti P, Rubolini D, Dunn PO, Fasola M (2003) Colour polymorphism in birds: causes and functions. J evol Biol 16:635-646

Gonzales G, Sorci G, de Lope F (1999) Seasonal variation in the relationship between cellular immune response and badge size in male house sparrows (Passer domesticus). Behav Ecol Sociobiol 46:117-122

Gratten J, Wilson AJ, McRae AF, Beraldi D, Visscher PM, Pemberton JM, Slate J (2008) A localised negative genetic correlation 
constrains microevolution of coat color in wild sheep. Science 319:318-320

Gross MR (1996) Alternative reproductive strategies and tactics: diversity within sexes. Trends Ecol Evol 11:92-98

Gustafsson L, Qvarnström A, Sheldon BC (1995) Trade-offs between life-history traits and a secondary sexual character in male collared flycatchers. Nature 375:311-313

Houtman AM, Falls JB (1994) Negative assortative mating in the white-throated sparrow, zonotrichia albicollis - the role of mate choice and intra-sexual competition. Anim Behav 48:377-383

Hughes KA, Rodd FH, Reznick DN (2005) Genetic and environmental effects on secondary sex traits in guppies (Poecilia reticulata). J Evol Biol 18:35-45

Järvi T, Bakken M (1984) The function of the variation in the breast stripe of the great tit (Parus major). Anim Behav 32:590-596

Järvi T, Røskaft E, Bakken M, Zumsteg B (1987) Evolution of variation in male secondary sexual characteristics: a test of eight hypotheses applied to pied flycatchers. Behav Ecol Sociobiol 20:161-169

Jawor JM, Gray RD, Beall SM, Breitwisch R (2004) Multiple ornaments correlate with aspects of condition and behaviour in female northern cardinals, Cardinalis cardinalis. Anim Behav 67:875-882

Jennions MD, Petrie M (1997) Variation in mate choice and mating preferences: a review of causes and consequences. Biol Rev $72: 283-327$

Johnstone RA (1995) Sexual selection, honest advertisement and the handicap principle: reviewing the evidence. Biol Rev 70:1-65

Jones IL (1990) Plumage variability functions for status signaling in least auklets. Anim Behav 39:967-975

Kassen R (2002) The experimental evolution of specialists, generalists, and the maintenance of diversity. J Evol Biol 15:173-190

Kawecki TJ, Ebert D (2004) Conceptual issues in local adaptation. Ecol Let 7:1225-1241

Kristin A, Valera F, Hoi C, Hoi H (2007) Do melanin-based tail patterns predict individual quality and sex in Lesser Grey Shrikes Lanius minor. J Ornithol 148:1-8

Meyer CI, Kaufman R, Cech JJ (2006) Melanin pattern morphs do not differ in metabolic rate: implications for the evolutionary maintenance of a melanophore polymorphism in the green swordtail, Xiphophorus helleri. Naturwissenschaften 93:495-499

Monney JC, Luiselli L, Capula M (1996) Body size and melanism in Vipera aspis in the Swiss Prealps and central Italy and comparison with different Alpine populations of Vipera berus. Rev Suisse Zool 103:81-100

Murton RK, Westwood NJ, Thearle RJ (1973) Polymorphism and the evolution of a continuous breeding season in the pigeon, Columba livia. J Reprod Fertil Suppl 19:563-77

Nakagawa S, Ockendon N, Gillespie DOS, Hatchwell BJ, Burke T (2007) Assessing the function of house sparrow's bib size using a flexible meta-analysis method. Behav Ecol 18:831-840

Nogueiras R, Wiedmer P, Perez-Tilve D, Veyrat-Durebex C, Keogh JM, Sutton GM, Pfluger PT, Castaneda TR, Neschen S, Hofmann SM, Howles PN, Morgan DA, Benoit SC, Szanto I, Schrott B, Schurmann A, Joost HG, Hammond C, Hui DY, Woods SC, Rahmouni K, Butler AA, Farooqi IS, O'Rahilly S, RohnerJeanrenaud F, Tschop MH (2007) The central melanocortin system directly controls peripheral lipid metabolism. J Clin Invest 117:3475-3488

Owens IPF, Burke T, Thompson DBA (1994) Extraordinary sex-roles in the Eurasian dotterel-Female mating arenas, female-female competition, and female mate choice. Am Nat 144:76-100
Parker TH, Stansberry BM, Becker CD, Gipson PS (2003) Do melanin- or carotenoid-pigmented plumage ornaments signal condition and predict pairing success in the Kentucky warbler. Condor 105:663-671

Phillips RA, Furness RW (1998) Polymorphism, mating preferences and sexual selection in the Arctic skua. J Zool Lond 245:245-252

Potti J, Montalvo S (1991) Male colour variation in Spanish pied flycatchers Ficedula hypoleuca. Ibis 133:293-299

Rosen RF, Tarvin KA (2006) Sexual signals of the male American goldfinch. Ethology 112:1008-1019

Roulin A (1999) Nonrandom pairing by male barn owls Tyto alba with respect to a female plumage trait. Behav Ecol 10:688-695

Roulin A (2002) Barn owl. Update of the Birds of the Western Paleartic 4:115-138

Roulin A (2004a) Proximate basis of the covariation between a melanin-based female ornament and offspring quality. Oecologia 140:668-675

Roulin A (2004b) The function of food stores in bird nests: observations and experiments in the barn owl Tyto alba. Ardea 92:69-78

Roulin A (2006) Linkage disequilibrium between a melanin-based colour polymorphism and tail length in the barn owl. Biol J Linn Soc Lond 88:475-488

Roulin A, Altwegg R (2007) Breeding rate is associated with pheomelanism in male and with eumelanism in female barn owls. Behav Ecol 18:563-570

Roulin A, Dijkstra C (2003) Genetic and environmental components of variation in eumelanin and phaeomelanin sex-traits in the barn owl. Heredity 90:359-364

Roulin A, Gasparini J, Bize P, Ritschard M, Richner H (2008a) Melanin-based colorations signal strategies to cope with poor and rich environments. Behav Ecol Sociobiol 62:507-519

Roulin A, Almasi B, Rossi-Pedruzzi A, Ducrest A-L, Wakamatsu K, Miksik I, Blount JD, Jenni-Eiermann S, Jenni L (2008b) Corticosterone mediates the condition-dependent component of melanin-based coloration. Anim Behav 75:1351-1358

Senar JC, Polo V, Uribe F, Camerino M (2000) Status signalling, metabolic rate and body mass in the siskin: the cost of being a subordinate. Anim Behav 59:103-110

Slagsvold T, Lifjeld JT (1988) Plumage colour and sexual selection in the pied flycatcher Ficedula hypoleuca. Anim Behav 36:395-407

Tarof SA, Dunn PO, Whittingham LA (2005) Dual functions of a melanin-based ornament in the common yellowthroat. Proc R Soc Lond B272:1121-1127

Taylor IR (1993) Age and sex determination of Barn Owls Tyto alba alba. Ring Migr 14:94-102

Tella JL, Forero MG, Donazar JA, Hiraldo F (1997) Is the expression of male traits in female lesser kestrels related to sexual selection. Ethology 103:72-81

Thusius KJ, Peterson KA, Dunn PO, Whittingham LA (2001) Male mask size is correlated with mating success in the common yellowthroat. Anim Behav 62:435-446

Vasquez T, Pfennig KS (2007) Looking on the bright side: females prefer coloration indicative of male size and condition in the sexually dichromatic spadefoot toad, Scaphiopus couchii. Behav Ecol Sociobiol 62:127-135

Wiehn J, Korpimäki E (1997) Food limitation on brood size: experimental evidence in the Eurasian kestrel. Ecology 78:2043-2050

Wunderle JM (1981) An analysis of a morph ratio cline in the bananaquit (Coereba flaveola) on Grenada, West Indies. Evolution 35:333-344 